\title{
Analytical Study on the Effective Flange Width for T-shaped Shear Walls
}

\author{
Nan Lu' ${ }^{1,2}$, Weibin $\mathrm{Li}^{1,2 *}$ \\ ${ }^{1}$ Key Laboratory of Concrete and Prestressed Concrete Structures of Ministry of Education, Southeast University, 210096, \\ Nanjing, China \\ 2 School of Civil Engineering, Southeast University, 210096, Nanjing, China \\ * Corresponding author, e-mail: 101000822@seu.edu.cn
}

Received: 17 July 2019, Accepted: 07 December 2019, Published online: 11 February 2020

\begin{abstract}
This study was organized to derive simplified expressions to estimate the effective flange width for T-shaped shear walls at different loading stages. For that purpose, the variation in the effective flange width was explored by introducing dimensionless effective flange width coefficient. According to the principle of minimum potential energy, the theoretical expression of the effective flange width coefficient in the elastic stage was obtained. Furthermore, a parametric study considering the axial load ratio, height-width ratio of flange and width-thickness ratio of the flange, as well as the section aspect ratio was conducted to determine the effective flange width using verified nonlinear finite-element models. In light of the parametric analysis results, a formula model was proposed depending on the axial load ratio and height-width ratio of flange. Finally, the predictions of the proposed simplified formulas were verified with the theoretical solutions or finite element (FE) results, which indicated that the proposed formulas can accurately capture the effective flange width at the elastic, yield and limit state.
\end{abstract}

\section{Keywords}

shear walls, shear lag effect, effective flange width, principle of minimum potential energy, FEM

\section{Introduction}

In elementary beam theory, the plane sections are assumed to remain planar after bending. Because of shear deformation caused by the shear flow, this assumption is erroneous for the special-section members. This phenomenon, which is referred to shear lag effect, has been investigated in beams [1], bridge decks [2, 3], etc.

The reinforced concrete shear walls are frequently used as the primary component of the lateral load-resisting system in high rise buildings [4]. However, the shear lag effect in shear walls significantly reduces their lateral strength and stiffness and enhances the normal stress at the web-flange junction, which is harmful for the seismic behavior of walls [5]. Multiple research investigations have been conducted to explore the effect of the shear lag on shear walls. Using the finite-element method, Kwan [6] carried out a parametric study to investigate the shear lag effect in wall structures with the shear lag in the webs of core walls into account. On the basis of analysis results, empirical formulas to estimate the shear lag effects were produced for practical applications. Luo and Li [7] studied the shear lag effect in the special-shaped short-leg shear wall under transverse force based on the calculation results of the spatial shell element structure model. Li et al. [8] verified that the flatshell element, which is composed of a plane stress element and a thin-plate bending element, could effectively analyze the shear lag effect of the short-pier shear wall in the elastic stage by the low cyclic loading test. Moreover, the analysis results indicated that the maximum normal stress position was changed with the loading cycle because of the stress redistribution in the plastic stage. Chaouch et al. [9] conducted a numerical study on RC wall with L-shaped section and the stress concentration in corner location, intersection between the two RC walls, was observed for all models.

Hassan and El-Tawil [10] investigated the effect of the variables that were not addressed in the ACI expression on the tension flange effective width adopting a detailed finite element model. Many suitable provisions for the implementation of performance-based design criteria were suggested. Zhang and Li [11] proposed a new method to calculate the influence of the shear lag effect in the flange of 
RC walls developed from the truss analogy for the cracked flange segment in tension. Compared with the test data, the fresh method has greater accuracy than the effective flange width method.

According to the variation principle, Li et al. [12] derived the governing equation and boundary condition by introducing a new displacement model considering the effect of the shear lag and shear deformation. Zhang et al. [13] deduced equations about the shear-lag coefficient and deformation of T-shaped short-leg shear wall and discussed the effects of different geometric parameters and load forms on the shear lag deformation. Ni and Cao [14] obtained the formulas of normal stress and deflection of T-shaped short-leg shear walls taking the additional deflection caused by the shear lag effect into account. Then, they established a calculation method of cracking load depending on the effective flange width.

Shear lag results in a nonlinear stress distribution of the flange, which complicates the analysis and design. To simplify the model, the normal stress is assumed to be uniformly distributed in the effective range $b_{e f f}$ of the flange. The definition is also presented in Fig. 1, where the curve is the normal stress distribution of flange, and $\sigma_{\max }$ is the maximum (max) normal stress of flange. The normalization of the effective flange width is helpful to identify the rule of shear lag in the flange. Defining $\eta$ as the effective flange width coefficient, the effective width of the flange, $b_{\text {eff }}$, can be expressed as follows:

$b_{e f f}=\eta b_{f}=\frac{\iint_{A_{f}} \sigma d A}{\int_{h_{f}} \sigma_{\max } d y}$

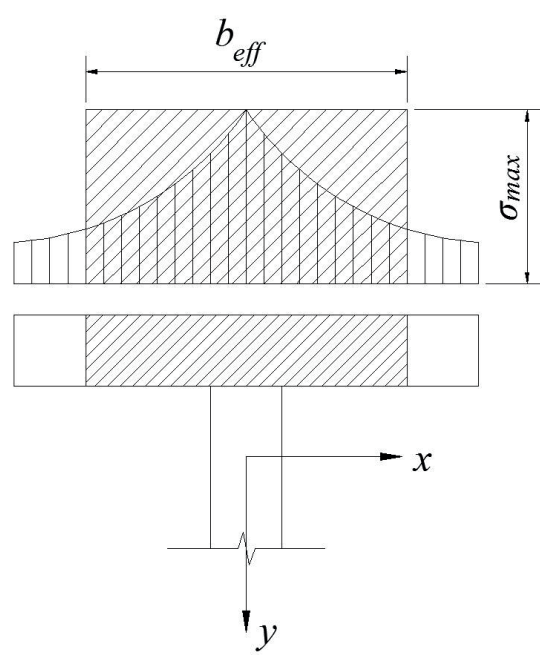

Fig. 1 Effective width of flange
In the existing research of shear walls, the expression for calculating the effective flange width in the elastic stage is mostly obtained by the principle of minimum potential energy and verified by numerical analysis or experimental results [15-18]. For the nonlinear analysis of the effective flange width in the plastic stage, the finite element modeling tool is used to evaluate the shear lag effect [19].

Although the results of the previous studies satisfy the accuracy requirements, the expressions are too complex to be suitable for engineering application. For simplification, Shi and Wang [20] derived the semi-theoretical and semi-empirical formulas for the effective flange width at different loading stages without the influence of the axial pressure on the shear lag effect.

Considering the coupling effect of the axial load and horizontal force in this paper, the simplified formulas of the effective flange width of T-shaped shear walls are derived at different loading stages. The longitudinal displacement function is built to propose a theoretical expression of the effective flange width in elastic stage, and the curve of the warping displacement function is determined by the theoretical analysis. The governing differential equation and corresponding boundary condition are constructed by applying the principle of minimum potential energy. However, there are no available experiments to verify the phenomenon, since the researchers focus on the capacity of shear walls instead of the stress distribution of the section. Lacking of accurate test data, a well-calibrated finite-element modeling tool was used to investigate the characteristic of the effective flange width at different stages. Key parameters that significantly affect the effective flange width are selected depending on the coefficient of determination $\left(R^{2}\right)$ between the effective flange width coefficient $(\eta)$ with the axial load ratio $(n)$, the height-width ratio of flange, the width-thickness ratio of flange and the section aspect ratio, respectively. The simplified formulas, which are composed of key parameters, are proposed to calculate the effective flange width coefficient of the shear lag effect in RC structural walls with a T-shaped section.

\section{Theoretical solution}

\subsection{Displacement function for shear lag warping}

Because of shear deformation, the longitudinal displacement of the cross section no longer satisfies the BernoulliEuler assumption, and additional deflection induced by the shear lag effect is viewed as the generalized displacement. As in Fig. 2, the coordinate origin is taken to coincide with the center of the cross section. 


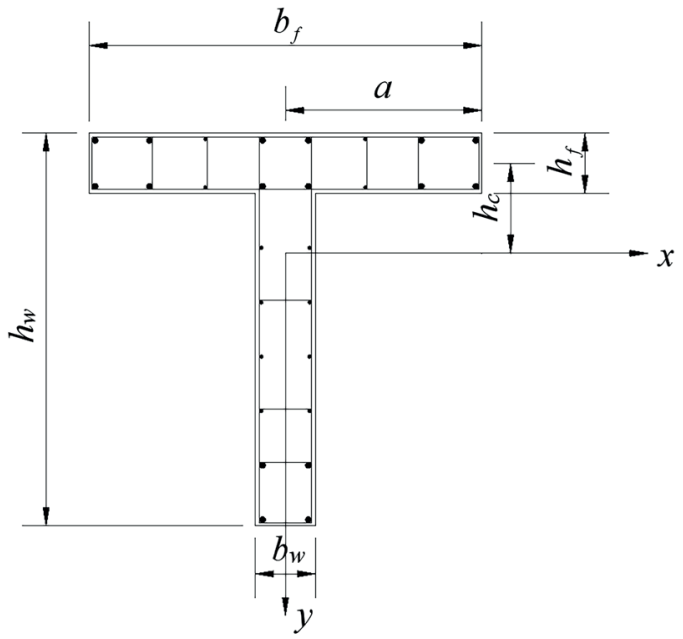

(a)

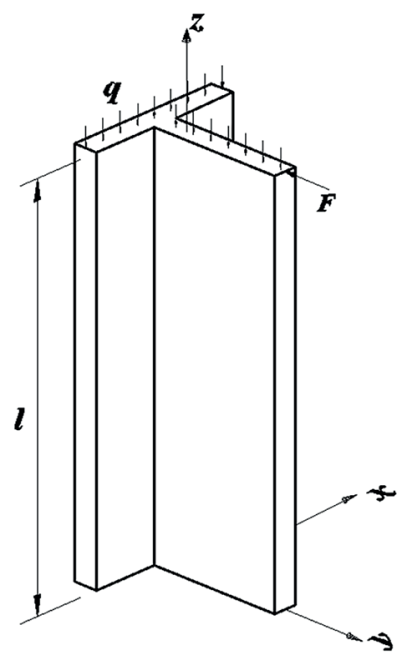

(b)

Fig. 2 The details of T-shaped shear wall: (a) cross section and coordinate system, (b) Force diagram

Based on the deformation characteristics of the structural member with flange $[14,16,21]$, the longitudinal displacement at any point of the cross section of the T-shaped shear walls consists of the section bending displacement, warping displacement and axial compression displacement, which can be expressed as

$$
u(x, y, z)=(-y)\left(\omega_{e}^{\prime}(z)+\omega_{a}^{\prime}(z)\right)+\zeta f(x, y) \omega_{a}^{\prime}(z)-\frac{q}{E} z,
$$

where $\omega_{e}$ is the deflection of the elementary beam, $\omega_{a}$ is the additional deflection caused by the shear lag effect, $\zeta$ is a self-equilibrium correction factor for warping stresses, and $f(x, y)$ is the warping displacement function for the shear lag. By setting $g(x, y)=\xi f(x, y)-y$, the Eq. (2) can be written as

$$
u(x, y, z)=(-y) \omega_{e}^{\prime}(z)+g(x, y) \omega_{a}^{\prime}(z)-\frac{q}{E} z .
$$

In essence, the shear lag effect is the phenomenon that the distribution of normal stress is non-uniform along the width of flange caused by the in-plane shear deformation [21]. Therefore, the warping displacement function for shear lag can be derived from shear deformation. Under a horizontal force, the shear stress at any point of the flange can be expressed as follows

$\tau=\frac{V S_{x}}{I_{x} h_{f}}=\frac{V h_{c}}{I_{x}}(a-x)$.

According to the theory of elasticity, the shear strain in flange is expressed as

$\gamma_{x z}=\frac{\partial u}{\partial x}+\frac{\partial v}{\partial z} \approx \frac{\partial u}{\partial x}=\frac{\tau}{G}$.

Where $u$ and $v$ are the displacement of $z$ and $x$ directions respectively. Assuming the effect of transverse displacement on shear deformation is negligible, $\frac{\partial v}{\partial z}$ could be ignored [21, 22]. Substituting Eq. (4) into Eq. (5) and integrating Eq. (5) with respect to $x$ give

$u=-\frac{V h_{c}}{I_{x} G}(a-x)^{2}+u_{0}$,

where $u_{0}$ is the longitudinal displacement at the end of the flange $(x=a), \mathrm{G}$ is the shear modulus, and $h_{c}$ is the distance from the flange axis to the coordinate origin.

From Eq. (6), it is theoretically proven that the longitudinal displacement of the flange is distributed as a quadratic parabola along the width of the flange, so the warping displacement function for the shear lag of T-shaped shear walls is assumed as

$f(x, y)=\left\{\begin{array}{ccc}y\left(1-\frac{(a-x)^{2}}{a^{2}}\right)+s & x \in[0, a] & \text { flange } . \\ s & \text { web }\end{array}\right.$

Constant $s$ is added to the entire cross section. The normal stress at any point on the cross section of the shear wall can be obtained by Eq. (8).

$\sigma=E \frac{\partial u}{\partial z}=-E y \omega_{e}^{\prime \prime}(z)+E \mathrm{~g}(x, y) \omega_{a}^{\prime \prime}(z)-q$

The warping normal stress caused by shear lag effect should conform to the equilibrium conditions without additional axial force and bending moment, thus

$\iint \sigma_{a} d A=E \omega_{a}^{\prime \prime}(z) \cdot \iint \mathrm{g}(x, y) d A=0$,

$\iint \sigma_{a} y d A=E \omega_{a}^{\prime \prime}(z) \cdot \iint \mathrm{g}(x, y) y d A=0$. 
Substituting Eq. (7) into Eq. (9), we obtain

$s=\frac{2 A_{f} h_{c}}{3 A}$,

where $A_{f}$ is the flange area, and $A$ is the whole section area. Substituting Eq. (7) into Eq. (10), we obtain the self-equilibrium correction coefficient $\zeta$

$\zeta=\frac{I_{x}}{I_{\xi x}}=\frac{\iint y^{2} d A}{\iint f(x, y) y d A}$,

where $I_{x}$ is the moment of inertia of the cross section, $I_{\zeta x}$ is the product of inertia of the cross section that corresponds to shear lag warping.

\subsection{Governing differential equation and its solution}

It is simplified that only the normal strain $\varepsilon_{z}$ and shear strain $\gamma_{x z}$ are considered

$\varepsilon_{z}=\frac{\partial u(x, y, z)}{\partial z}=-y \omega_{e}^{\prime \prime}(z)+g(x, y) \omega_{a}^{\prime \prime}(z)-\frac{q}{E}$

$\gamma_{x z}=\frac{\partial u(x, y, z)}{\partial x}=g_{x}(x, y) \omega_{a}^{\prime}(z)$

From Eq. (9) and Eq. (10), $\iint y g(x, y) d A=0$ and $\iint g(x, y) d A=0, \iint y d A=0$.Thus, the strain energy of the shear wall can be written in the following form

$U=\frac{1}{2} \int_{V}\left(E \varepsilon^{2}+G \gamma^{2}\right) d v$

$=\frac{1}{2} \int_{0}^{l} E\left\{I_{x}\left(\omega_{e}^{\prime \prime}\right)^{2}+I_{g}\left(\omega_{a}^{\prime \prime}\right)^{2}+\left(\frac{q}{E}\right)^{2} A\right\}+G A_{g}\left(\omega_{a}^{\prime}\right)^{2} d z$.

Where $A_{g}=\iint g_{x}^{2}(x, y) d A \quad I_{g}=\iint g^{2}(x, y) d A$.

The potential energy of the load system can be expressed as follows

$V=\int_{0}^{l} M(z)\left(\omega_{e}^{\prime \prime}+\omega_{a}^{\prime \prime}\right) d z-\left.\iint q u\right|_{z=l} d A$.

By synthesizing the above equations, the total potential energy of T-shaped shear walls can be given easily as

$\Pi=U-V=\frac{1}{2} \int_{0}^{l}\left[E I_{x}\left(\omega_{e}^{\prime \prime}\right)^{2}+E I_{g}\left(\omega_{a}^{\prime \prime}\right)^{2}+G A_{g}\left(\omega_{a}^{\prime}\right)^{2}+\frac{q^{2}}{E} A\right] d z$

$-\int_{0}^{l} M(z)\left(\omega_{e}^{\prime \prime}+\omega_{a}^{\prime \prime}\right) d z+\left.\iint q u\right|_{z=l} d A$.

According to the principle of minimum potential energy, $\delta \Pi=0$ The first-order variation for the total potential energy can be described by $\delta \Pi=\delta \omega_{e}^{\prime \prime} \int_{0}^{l}\left[E I_{x} \omega_{e}^{\prime \prime}-M(z)\right] d z-\delta \omega_{a}^{\prime} \int_{0}^{l}\left[E I_{g} \omega_{a}^{\prime \prime \prime}-F-G A_{g} \omega_{a}^{\prime}\right] d z$

$+\delta \omega_{a}^{\prime}\left[E I_{g} \omega_{a}^{\prime \prime}-M(z)\right]_{0}^{l}$.

From Eq. (18), the governing differential equations and natural boundary condition can be easily derived as follows

$E I_{x} \omega_{e}^{\prime \prime}-M(z)=0$,

$\omega_{a}^{\prime \prime \prime}-K^{2} \omega_{a}^{\prime}=\frac{F}{E I_{g}}$,

$\delta \omega_{a}^{\prime}\left[E I_{g} \omega_{a}^{\prime \prime}-M(z)\right]_{0}^{l}=0$,

where $K=\sqrt{G A_{g} / E I_{g}}$ is Reissner's parameter. $M(z)$ is the bending moment at any cross section, i.e., $M(z)=F(l-z)$.

For a fixed end, $\left.\omega_{e}\right|_{z=0}=0,\left.\omega_{e}^{\prime}\right|_{z=0}=0$ and $\omega_{e}$ can be solved as

$\omega_{e}(z)=\frac{F}{6 E I_{x}}\left(3 l z^{2}-z^{3}\right)$.

As for Eq. (20), we can express the general solution as follow

$\omega_{a}=c_{1} \sinh K z+c_{2} \cosh K z+c_{3}-\frac{F z}{K^{2} E I_{g}}$.

Noting that $\left.\omega_{a}\right|_{z=0}=0,\left.\omega_{a}^{\prime}\right|_{z=0}=0$, and from Eq. (21), $\left.\omega_{a}^{\prime \prime}\right|_{z=l}=0$ can be derived. Then Eq. (23) can be solved as

$\omega_{a}(z)=\frac{F}{K^{3} E I_{g}} \sinh K z-\frac{F z}{K^{2} E I_{g}}+\frac{F \tanh K l}{K^{3} E I_{g}}(1-\cosh K z)$

$=\frac{F}{K^{3} E I_{g}}[\sinh K z-K z+\tanh K l(1-\cosh K z)]$.

Substituting Eq. (22) and Eq. (24) into Eq. (8), the theoretical formula of normal stress can be expressed easily as

$$
\begin{aligned}
& \sigma_{f}(x, y, z)=\frac{F(l-z)}{I_{x}} y-q \\
& +\frac{F\left[\zeta\left[y\left(1-\frac{(a-x)^{2}}{a^{2}}\right)+s\right]-y\right]}{K I_{g}}(\tanh K l \cosh K z-\sinh K z) .
\end{aligned}
$$

Letting $x=0$ in Eq. (25), we can establish the peak stress on the symmetry axis of the flange in relation to $\mathrm{y}$ and $z$

$\sigma_{f \max }(y, z)=\frac{F(l-z)}{I_{x}} y-q$

$+\frac{F[\zeta s-y]}{K I_{g}}(\tanh K l \cosh K z-\sinh K z)$, 
where the positive directions of the symbols in the expression are shown in Fig. 2. Substituting Eq. (25) and Eq. (26) into Eq. (1), we obtain the effective flange width as follows

$$
\begin{aligned}
b_{e f f}= & \frac{-\frac{F(l-z)}{I_{x}} h_{c} A_{f}-\frac{F(\sinh K z-\tanh K l \cosh K z)}{K I_{g}}\left(-\frac{2}{3} \zeta h_{c} A_{f}+\zeta s A_{f}+h_{c} A_{f}\right)-q A_{f}}{-\frac{F(l-z)}{I_{x}} h_{c} h_{f}-\frac{F(\sinh K z-\tanh K l \cosh K z)}{K I_{g}}\left(\zeta s h_{f}+h_{c} h_{f}\right)-q h_{f}} \\
= & 2 a\left(1-\frac{\frac{2 \zeta h_{c}}{3 K I_{g}}(\sinh K z-\tanh K l \cosh K z)}{\frac{l-z}{I_{x}} h_{c}+\frac{\zeta s+h_{c}}{K I_{g}}(\sinh K z-\tanh K l \cosh K z)+\frac{q}{F}}\right)=2 a \eta
\end{aligned}
$$

The effective width $b_{\text {eff }}$ can be non-dimensionalized as the effective flange width coefficient $\eta$ :

$$
\eta=1-\frac{\frac{2 \zeta h_{c}}{3 K I_{g}}(\sinh K z-\tanh K l \cosh K z)}{\frac{l-z}{I_{x}} h_{c}+\frac{\zeta s+h_{c}}{K I_{g}}(\sinh K z-\tanh K l \cosh K z)+\frac{q}{F}} .
$$

\section{Finite element model and verification}

\subsection{Finite element model}

For the analysis of shear lag effect of the shear wall, a 3D nonlinear finite element model of the T-shaped shear wall with an axial load and a horizontal force applied at the top is created using the analysis program ANSYS 14.0 [23]. The stress of the steel bar plays an important role in defining the loading stage. Thus, the volumes are accurately divided by the command VSBW to build the steel bar model. SOLID 65 and LINK 8 are used for the concrete and steel bar respectively, as shown in Fig. 3, and the ideal bonding behavior between concrete and reinforcing steel is assumed.

\subsubsection{Material models}

Concrete, which is a quasi-brittle material that accounts for both cracking and crushing failure modes, behaves significantly different under tension and compression. The computer program implementation of the concrete material model employs SOLID 65 following the five-parameter Willam-Warnke failure criterion [24].

The uniaxial compressive behavior of concrete is modeled based on the nonlinear stress-strain relation, in this research, which is given by Chinese code for design of concrete structures GB50010-2010 [25]. The multilinear curve of the stress-strain relation for concrete is shown in Fig. 4(a). $f_{c}$ is the compressive strength of concrete, $\varepsilon_{c u}$ is the ultimate compressive strain of the concrete, and $\varepsilon_{0}$ is the compressive strain corresponding to the compressive strength. According to GB50010, we can obtain $\varepsilon_{0}=0.002$ and $\varepsilon_{c u}=0.0033$. Multilinear Isotropic Hardening (MISO) is used for the concrete constitutive [24]. It should be noted that the slope of the first segment of the curve is determined by the elastic modulus of concrete, and the other segment slopes should be smaller than that of the first segment, but all segments slope are greater than zero.

The stress-strain relation of concrete in tension is assumed to be isotropic and linearly elastic up to the tensile strength $\left(f_{t}\right)$, as displayed in Fig. 4(b). The tensile property of concrete is significantly weaker than the compressive property, so the concrete easily cracks. In ANSYS [23], a plane of weakness normal to the crack face is introduced to represent the existence of a crack. Upon cracking, the principal tensile stress gradually reduces to zero, which is identical to the elastic modulus of the concrete element in this direction, as shown in Fig. 4(b). Furthermore, considering the shear strength loss caused by cracking, a shear transfer

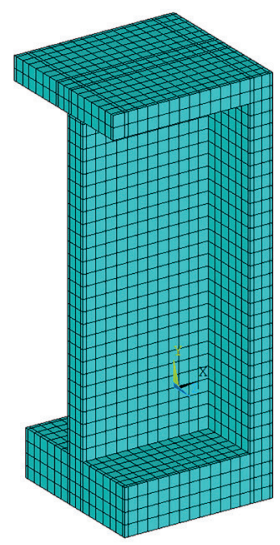

(a)

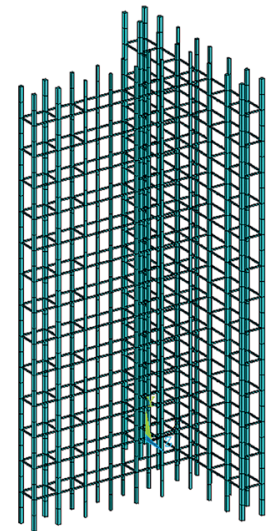

(b)
Fig. 3 Stress-strain relation of: (a) concrete under compression, (b) concrete under tension
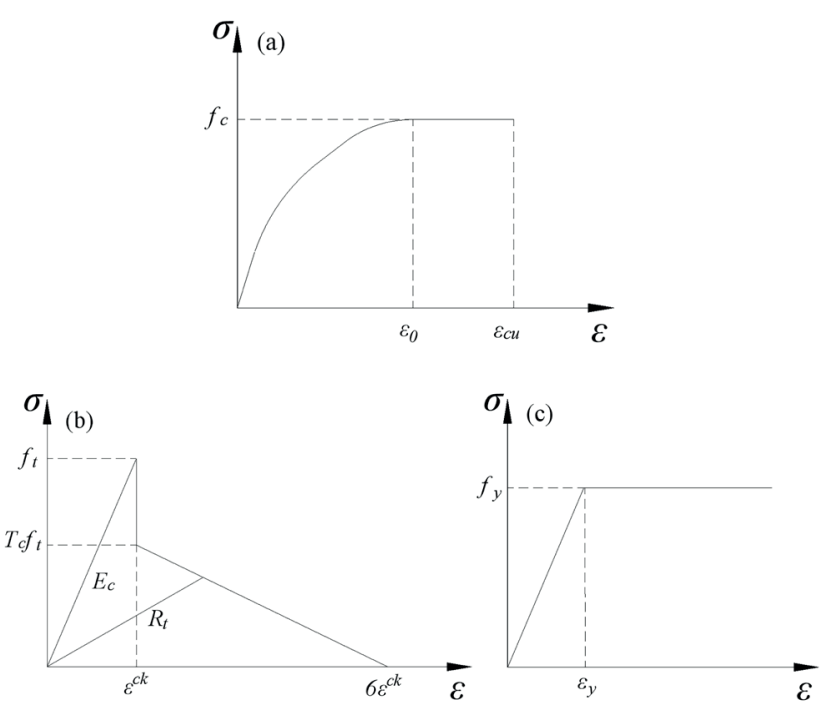

Fig. 4 Stress-strain relation of: (a) concrete under compression, (b)concrete under tension, (c) steel bar 
coefficient $\beta_{t}$ is used to reduce the shear strength. When the crack is closed, the loss of stress transmitted across the crack is determined by the shear transfer coefficient $\beta$. In Fig. 4(b), $E_{c}$ is the elastic modulus of concrete; $T_{c}$ is a multiplier for the amount of tensile stress relaxation and defaults to 0.6 . Considering the tensile stress relaxation after cracking, i.e., KEYOPT (7) $=1$, the secant slope $R_{t}$ adaptively decreases and reduces to zero when the solution converges. In this research, the shear transfer coefficient is $\beta_{t}=0.125$ for an open crack and $\beta_{c}=0.95$ for a closed crack [24]. Other material parameters of concrete are consistent with the results of the material test [26].

The behavior of the steel bar is assumed to be elastic-perfectly plastic and the same in tension and compression, as shown in Fig. 4(c). Therefore, the stress-strain relation can be modeled by bilinear isotropic hardening (BISO) using von Mises yield criterion. The slope of the first segment of the curve is the elastic modulus of steel bar $E_{s}$. The Poisson ratio $(v)$ and yield stress $(f)$ are also required to specify the behavior. In this research, the Poisson ratio is taken as 0.3 , and the other parameters are consistent with the tests.

\subsubsection{Meshing and boundary conditions}

For the verification of model, three tested T-shaped RC shear walls [26] are modeled with same material properties and details. The mesh density also plays an important role in the analysis. The sparser the mesh is, the lower the computing precision is. On the other hand, the denser the mesh is, the longer the computing time is. After lots of preliminary analyses, the optimal element size is set to $100 \mathrm{~mm}$. The wall model and steel bar model are displayed in Fig. 3.

To ensure that the model acts the same way as the experimental wall, the boundary conditions are applied accurately. For the simulation of the axial compression, an axial constant uniform load is applied at the top of the wall. The nodes at the bottom of the wall are fixed in all directions. The degrees of freedom of all nodes on the horizontal loading plane are coupled in the loading direction. A monotonic load is applied on the plane using the displacement control method. The gravity of the shear walls is also taken into account.

\subsection{Model verification}

Only when the numerical results agree with experiment data, the FE model can be used for further research. For that purpose, the T-shaped shear wall specimen (SDT650) tested by Li [26] is molded. A satisfying result is obtained by setting the properties of the model, as shown in Fig. 5. In order to verify that the modeling method can sever for the parameter study, two more shear wall specimens (SDT800, SDT500) are analyzed, which are only adjusted in term of the details of steel bar and dimension of the walls. The validation of the nonlinear finite-element analysis procedure is presented in Fig. 5. It can be easily seen from Fig. 5 that the calculated load-displacement curves of the three models are both agree quite well with the experimental skeleton curves. Thus, the modeling method is validated and suitable for further research.

The normal stress contour of the T-shaped shear wall is shown in Fig. 6. As shown in the figure, the normal stress of the flange remote from the web-flange junction lags behind that at the junction, that is, a significant shear lag effect occurs in the flange. The calculated results present the stress distribution of the flange section reliably. Thus, there is no doubt that the effective flange width can be analyzed by this molding method.

\section{Discussion of the results}

\subsection{Modeling parameters}

In order to easily obtain the trait of the effective flange width of the T-shaped shear wall, the effective flange width coefficient is first studied in this paper. Eq. (28) shows that the effective flange width coefficient is related to the size of the specimen and axial load. According to the test specimens, the sizes of the finite element models are defined as follows: the wall heights are 800,1400 and $2000 \mathrm{~mm}$. The wall thickness is $100 \mathrm{~mm}$; the flange and web width have three dimensions of 500, 650 and $800 \mathrm{~mm}$. A limited axial load ratio of the shear walls is 0.5 as specified in the GB50010. Thus, the axial load ratios (n) are 0.1, 0.2, 0.3, 0.4 , and 0.5 . In total, 135 FEM combinations are modeled by combining these parameters with each other.

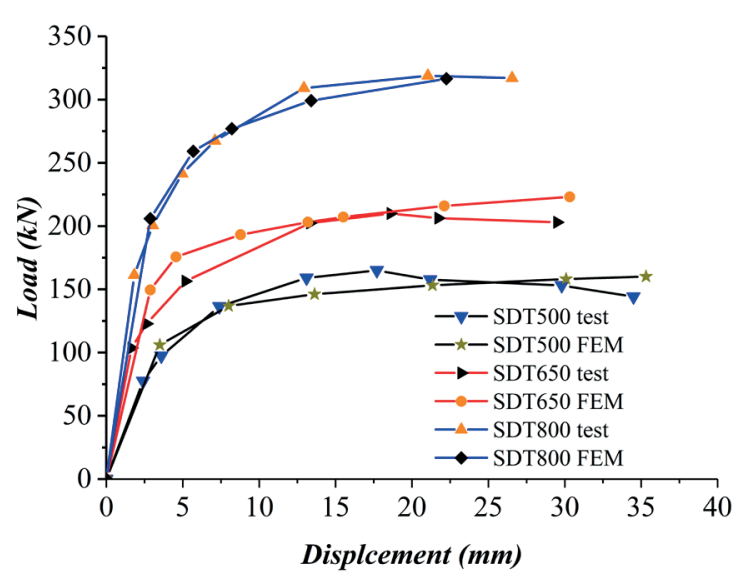

Fig. 5 Comparison between the experimental and analytical Loaddisplacement curves 

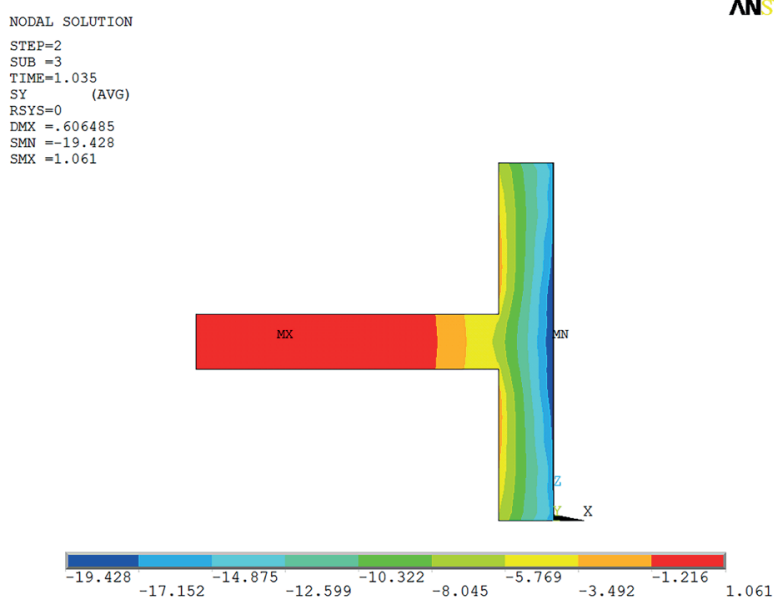

(a)

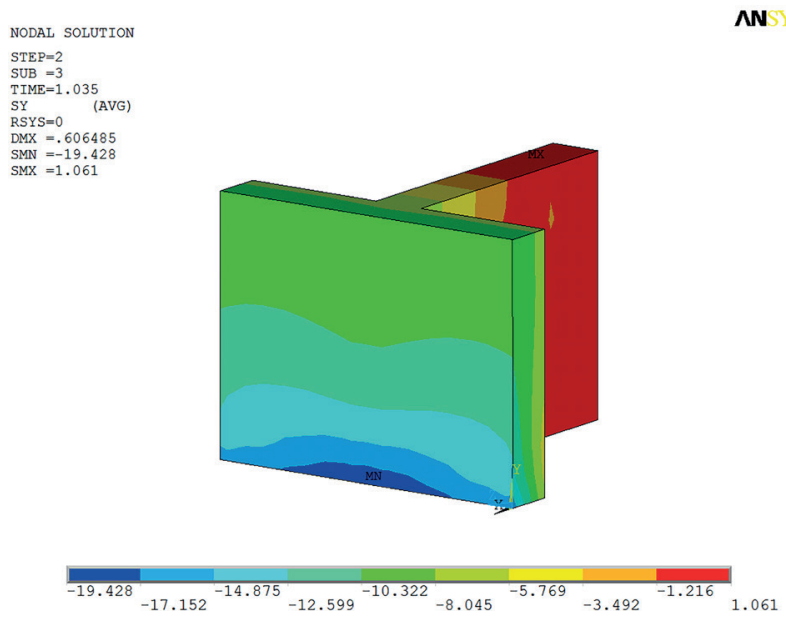

(b)

Fig. 6 normal stress contour of wall: (a) the section, (b) the bottom

To coincide with the test specimens, the axial compressive strength of concrete is taken as $30.8 \mathrm{MPa}$, while the yield stresses of the longitudinal steel bars are $295 \mathrm{MPa}$ and $345 \mathrm{MPa}$ for \# 8 and \# 12, respectively, and the yield stress of stirrup \# 4 is $730 \mathrm{MPa}$.

The effective width coefficient of flange $\eta$ is displayed against different parameters in Fig. 7. Among five axial load ratios, the coefficient increases with the augment of the axial load ratio, as shown in Fig. 7(a). The enhancement of the section normal stress mainly relies on axial load, which weakens the effect of the shear deformation, and leads to the trend. Owing to the cross section of the flange can be fully developed, a more uniform stress distribution of the section corresponds to a weaker the shear lag effect. The formula in Fig. 7(a) is obtained by the regression of the numerical results.

The effect of the height-width ratio of the flange on the effective flange width coefficient is prominent, as plotted in Fig. 7(b). If the width of the flange is constant, the
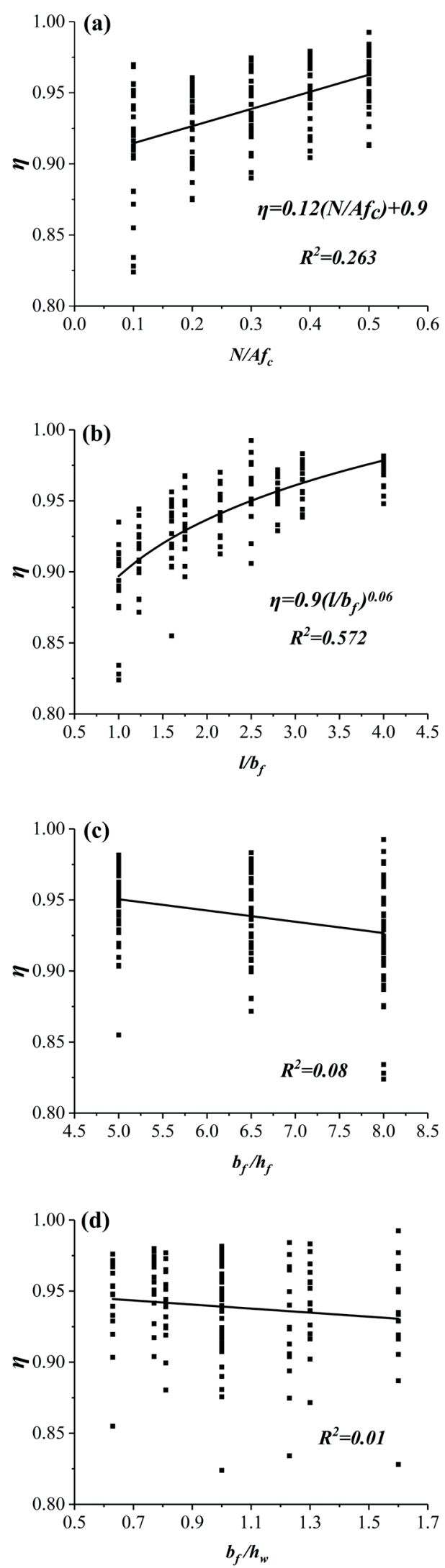

Fig. 7 The effective flange width coefficients with respect to parameters: (a) axial load ratio, (b) height-width of flange, (c) width-thickness ratio of flange, (d) section aspect ratio 
increase in wall height results in the bending deformation becoming the main deformation, whereas the shear deformation decreases. Thus, the lag phenomenon of normal stress in the transfer process is mitigated. On the contrary, the wider the flange is, the longer the normal stress transfer path of the section is, so the attenuation of normal stress is aggravated. Hence the effective flange width coefficient increases with the expansion of the height-width ratio of the flange. A power formula perfectly matches the relation between aspect ratio and effective flange, as shown in Fig. 7(b).

From Figs. 7(c)-(d), the trend can be discovered that the effective flange width coefficient decreases as the width-thickness ratio of the flange and the section aspect ratio increases, but this trend is so slight that it is negligible. The with-thickness ratio has a slight effect on the effective flange width coefficient, although it significantly impact on capacity of shear walls. In view of the above discussion, the axial load ratio and height-width ratio of the flange are the key parameters on the influence of the effective width coefficient of the flange. Thus, the following function model is constructed where $\alpha_{1}, \alpha_{2}, m$ and $C$ are determined by the data fitting.

$\eta=\alpha_{1}\left(\frac{N}{A f_{c}}+\alpha_{2}\right)\left(\frac{l}{b_{f}}\right)^{m}+C$

\subsection{Simplified expressions for the effective flange width}

The shear lag effect is most obvious at the bottom of the wall limb and gradually attenuates along the height of the wall, as shown in Fig. 6 (b). Thus, the stress of the section at the bottom of the flange as the object is extracted to obtain the effective flange width based on the previous definition. The effective flange width coefficients of 135 models at different loading stages are used to derive the following simplified formulas.

\subsubsection{Simplified expressions in elastic stage}

As stated previously, the theoretical solution of the effective flange width coefficient is too complex to apply to engineering. For the simplification in the elastic stage, the third sub-step results of all finite element models are obtained, then, the nonlinear fitting of Eq. (29) is conducted using the Levenberg-Marquardt algorithm (1Stopt user manual) [27]. After $\alpha_{1}, \alpha_{2}, m$ and $C$ are determined, a simplified formula for the effective flange width coefficient in the elastic stage is proposed as follows:

$\eta=0.2\left(\frac{N}{A f_{c}}-0.9\right)\left(\frac{l}{b_{f}}\right)^{-0.82}+1.01$
However, the first part of the Eq. (30) is negative in the engineering range of the axial load ratio, which makes the first part decrease with the increase in the height-width ratio of flange, namely the increase of the height-width ratio of the flange enlarges the effective flange width coefficient. The effective flange width coefficient predictions using Eq. (30) are compared with the finite element analysis results in Fig. 8(a). From this figure, it can be seen directly that the fitting is perfect with the coefficient of determination $\left(\mathrm{R}^{2}\right)$ of 0.90 . Consequently, Eq. (30) can replace the FEM to achieve a reasonable estimate of the effective flange width in the elastic stage.

Obtaining the horizontal force is crucial to the theoretical solution of the effective flange width coefficient. The third sub-step horizontal loads are extracted by time-history post-processing and substituted into Eq. (28). Fig. 8(b) compares the theoretical solutions obtained by Eq. (28) with the FEM results. The deviation indicates that the theoretical solutions underestimate the true values and are less than the simplified predictions, which can
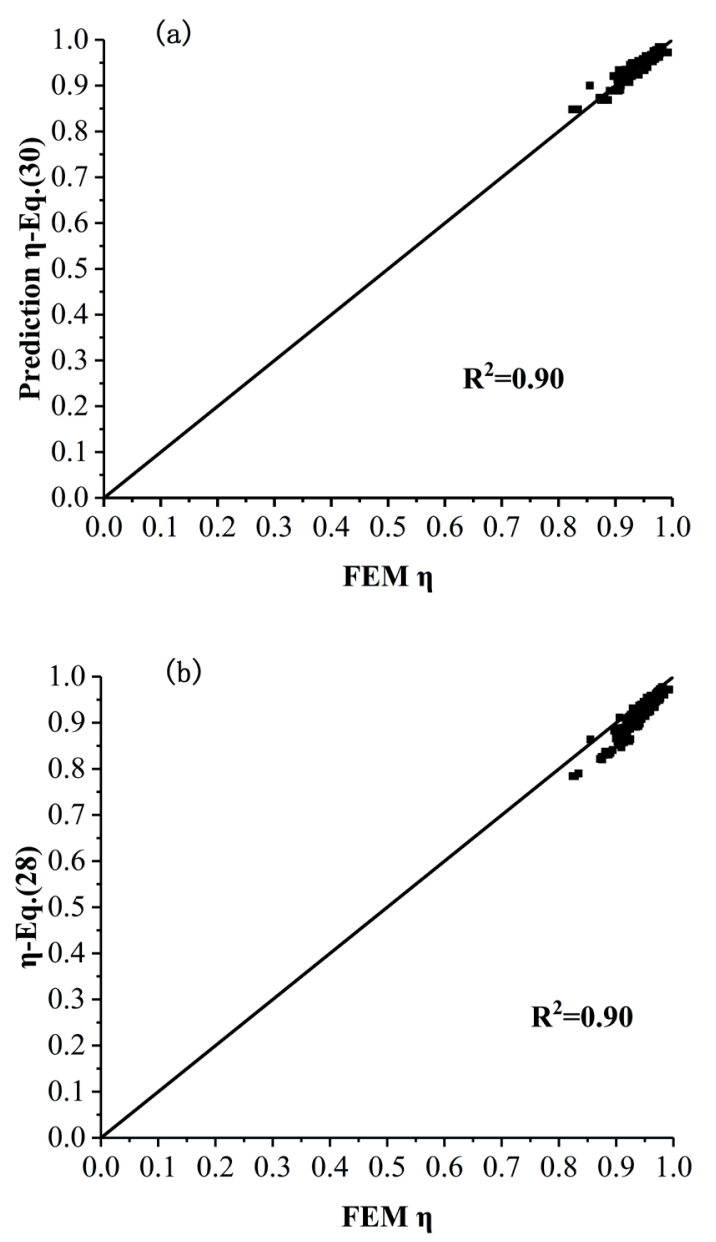

Fig. 8 Comparison of $\eta$ obtained from FEM analysis results with (a) simplified predictions by Eq. (30), (b) theoretical solutions in elastic stage 
be attributed to the assumption of the theoretical analysis that neglects the shear deformation in the web as well as the lateral and out-plane deformation of the flange. It can be concluded that the simplified predictions replacing the FEM results are more in accord with the actual condition of walls than the theoretical solutions. Moreover, the analysis shows that the difference between them is small. Limited by the space, 6 models corresponding to the experiment [26] from 135 combinations are selected for the error analysis. The parameters, simplified predictions, theoretical solutions and error values of the 6 models are listed in Table 1. The error values in Table 1 are within $5.21 \%$, and even the maximum error of all models is just $7.73 \%$. Therefore, the difference can be tolerated and the application of the simplified expression is feasible and accurate.

\subsubsection{Simplified expressions at yield}

To extract the normal stress on the cross section of flange at yield, the yield of the wall is defined as the steel bar at the base of the wall yield by tensile. According to the stress equivalent principle as Eq. (1), the effective flange width coefficient is obtained. Following the same method as in the elastic stage, the simplified formula of the effective flange width coefficient at yield is

$$
\eta=\left(\frac{N}{A f_{c}}-0.54\right)\left(\frac{l}{b_{f}}\right)^{-1.64}+0.98 .
$$

The FEM results and simplified prediction are compared in Fig. 9(a), and the coefficient of determination $\left(\mathrm{R}^{2}\right)$ is 0.91 . At this stage, the effect of the height-width ratio of flange on the prediction is more prominent.

\subsubsection{Simplified expressions in the limit state}

In the whole process, the sub-step that corresponds to the ultimate bearing capacity of each member is taken as the limit state. In the limit state, the axial load ratio is the major determinant of the compression zone depth and

Table 1 Comparison of the theoretical results and prediction results

\begin{tabular}{lccccc}
\hline Specimen & $n$ & $l / b_{f}$ & $\begin{array}{c}\text { simplified } \\
\text { prediction [1] }\end{array}$ & $\begin{array}{c}\text { theoretical } \\
\text { solution [2] }\end{array}$ & $([1]-[2]) /[1]$ \\
\hline SDT500-01 & 0.2 & 2.8 & 0.9493 & 0.9427 & $0.70 \%$ \\
SDT500-02 & 0.3 & 2.8 & 0.9580 & 0.9506 & $0.78 \%$ \\
SDT650-03 & 0.2 & 2.15 & 0.9346 & 0.9073 & $2.92 \%$ \\
SDT650-04 & 0.1 & 2.15 & 0.9237 & 0.8892 & $3.74 \%$ \\
SDT800-05 & 0.2 & 1.75 & 0.9207 & 0.8828 & $4.11 \%$ \\
SDT800-06 & 0.1 & 1.75 & 0.9078 & 0.8605 & $5.21 \%$ \\
\hline
\end{tabular}
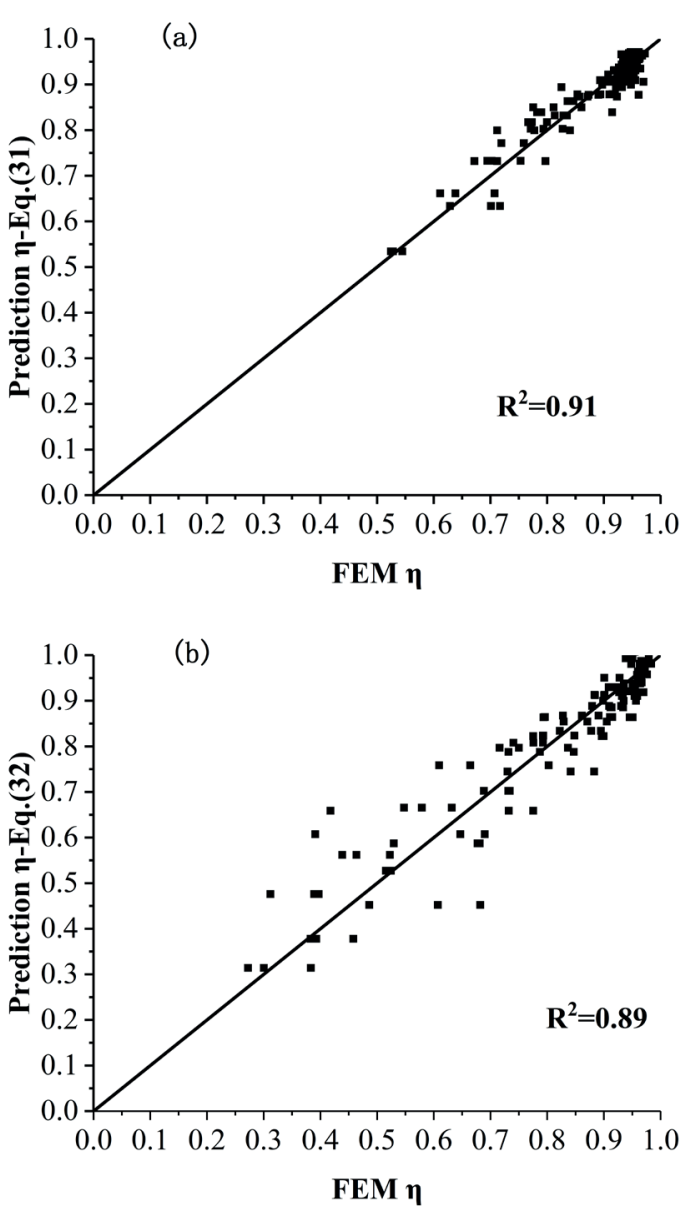

Fig. 9 Comparison of $\eta$ obtained from FEM analysis results with simplified prediction by (a) Eq. (31) at yield, (b) Eq. (32) in the limit state

no longer conforms to the linear relationship with $\eta$. The analysis of normal stress shows that a power formula better matches than the linear one for the relation between the axial load ratio and the effective flange width coefficient. Eq. (29) is modified to derive the simplified formula of the effective flange width coefficient in the limit state, which is expressed as follows

$\eta=1.14-0.13\left(\frac{N}{A f_{c}}\right)^{-0.8}\left(\frac{l}{b_{f}}\right)^{-0.39}$.

The simplified predictions are compared with the FEM results, as shown in Fig. 9(b), and the coefficient of determination $\left(\mathrm{R}^{2}\right)$ is 0.89 . Fig. 9 (b) shows that the simplified prediction in the limit state is discrete because of the compression zone depth of the section with a low axial load ratio is less than half of the thickness of the flange, and even the tensile stress appears at the two ends of the flange. We can easily calculate the effective flange width by Eq. (1) after the simplified formulas of the effective flange width coefficients at different loading stages were obtained. 


\subsection{Verification of the proposed formula}

Because of the shear lag effect, the stress on the flange of T-shaped shear wall is not uniformly distributed in the compressed flange. If the stress distribution is arbitrarily considered to be uniform, the calculation of the depth of the compression zone $x$ is smaller than actuality. In the limit state, $x$ even less than $2 a_{s}^{\prime}$ means that the steel compression are not yielding, which is obviously inconsistent with the actual force of the shear wall. Therefore, introducing the effective flange width $\left(b_{\text {eff }}\right)$ into the bearing capacity calculation can make a more accurate judgment of the position of the compression zone. According to Chinese technical specification for concrete structures of tall building JGJ3-2010 [28], calculation diagram of the T-shaped shear wall with the flange under compression is shown in Fig. 10.

From the force and moment equilibrium $\Sigma N=0$, $\Sigma M=0$, it can be obtained that

$$
\begin{aligned}
& N=A_{s}^{\prime} f_{y}^{\prime}-A_{s} \sigma_{s}-N_{s w}+N_{c}, \\
& M=A_{s}^{\prime} f_{y}^{\prime}\left(h_{w 0}-a_{s}^{\prime}\right)-M_{s w}+M_{c}-N\left(h_{w 0}-h_{c}-\frac{h_{f}}{2}\right) .
\end{aligned}
$$

Where $h_{w 0}=h_{w}-a_{s}, A_{s}^{\prime}=\rho_{s}^{\prime} b_{\text {eff }} x$. According to the depth of the compression zone, $\mathrm{T}$ section can be classified into two types, shown in Fig. 11. thus, $N_{c}$ and $M_{c}$ have two cases.

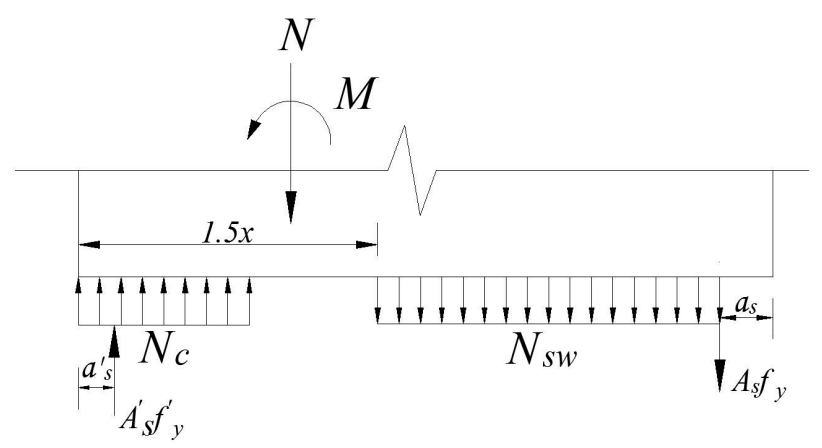

Fig. 10 Calculation diagram of a $\mathrm{T}$ section with the flange under compression

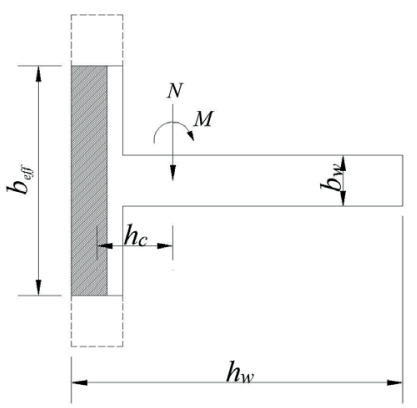

(a)

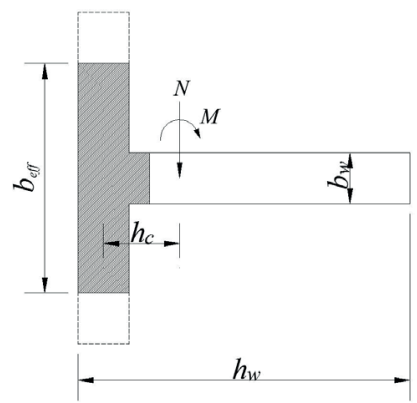

(b)
Fig. 11 Stress distributions in the compressed flange of a $\mathrm{T}$ section
For $x \leq h_{f}$

$N_{\mathrm{c}}=\alpha_{1} f_{c} b_{e f f} x$

$M_{\mathrm{c}}=\alpha_{1} f_{c} b_{e f f} x\left(h_{w 0}-\frac{x}{2}\right)$

For $x>h_{f}$

$N_{\mathrm{c}}=\alpha_{1} f_{c} b_{w} x+\alpha_{1} f_{c}\left(b_{e f f}-b_{w}\right) h_{f}$

$M_{\mathrm{c}}=\alpha_{1} f_{c} b_{w} x\left(h_{w 0}-\frac{x}{2}\right)+\alpha_{1} f_{c}\left(b_{\text {eff }}-b_{w}\right) h_{f}\left(h_{w 0}-\frac{h_{f}}{2}\right)$

According to the plane section assumption, when the concrete with the strength grade of no more than $C 50$, the actual depth of the compression zone $x_{n}=x / \beta_{1}=1.25 x$. That is, the steel with a range of $0.25 x$ each in the tension area and the compression zone has not yielding. For simplicity, the contribution of the concrete in the tension zone is neglected, and all steels in the tension area, beyond $h_{w 0}-1.5 x$, are yielding .

When $x \leq \xi_{b} h_{w 0}$, we can obtain $\sigma_{s}, N_{s w}, M_{s w}$ and expressed as

$\sigma_{s}=f_{y}$,

$N_{s w}=\left(h_{w 0}-1.5 x\right) b_{w} f_{y w} \rho_{w}$,

$M_{s w}=\frac{1}{2}\left(h_{w 0}-1.5 x\right)^{2} b_{w} f_{y w} \rho_{w}$.

While $x>\xi_{b} h_{w 0}$, all steels in the tension area are not yielding, so $N_{s w}=0, M_{s w}=0$.

Substituting x obtained from Eq. (33) into Eq. (34), we have the bearing capacity $F=M / L$. In order to verify the accuracy of the simplified formula, the calculated bearing capacity of 8 specimen and the shear wall test results [26] are tabulated in the in Table 2.

It can be seen from Table 2 that the bearing capacity calculations of the T-shaped shear wall using $b_{\text {eff }}$ are close to test data, therefore, the application of the simplified formula proposed in this study on the effective flange width prediction is feasible and accurate.

\section{Conclusions}

An analytical study on the effective flange width for T-shaped shear walls has been carried out under axial load and horizontal force in this paper. The following conclusions are drawn from the analysis:

1. A quadratic parabola was proven to be reasonable as the shear lag warping displacement function in the shear lag effect analysis of T-shaped shear walls depends on the shear deformation. Furthermore, para- 
Table 2 Comparison between the calculated values and the experiment values

\begin{tabular}{|c|c|c|c|c|c|c|}
\hline NO. & Specimen & $n$ & $l / b_{f}$ & Calculation $(\mathrm{kN})$ [1] & Experiment $(\mathrm{kN})[2]$ & $([2]-[1]) /[2](\%)$ \\
\hline 1 & SDT500-01 & 0.2 & 2.8 & 113.8 & 117.5 & $3.18 \%$ \\
\hline 2 & SDT500-02 & 0.4 & 2.8 & 152.7 & 165.0 & $7.47 \%$ \\
\hline 3 & SDT650-03 & 0.2 & 2.15 & 186.0 & 210.0 & $11.42 \%$ \\
\hline 4 & SDT650-04 & 0.1 & 2.15 & 145.1 & 161.0 & $9.90 \%$ \\
\hline 5 & SDT800-05 & 0.2 & 1.75 & 269.5 & 319.0 & $15.52 \%$ \\
\hline 6 & SDT800-06 & 0.1 & 1.75 & 206.3 & 230.0 & $10.29 \%$ \\
\hline 7 & SDT900-07 & 0.2 & 1.56 & 337.2 & 352.3 & $4.30 \%$ \\
\hline 8 & SDT900-08 & 0.1 & 1.56 & 256.4 & 296.8 & $13.60 \%$ \\
\hline
\end{tabular}

meter $s$ was introduced into the warping function for the equilibrium conditions of the bending moment and axial force considering the shear lag effect.

2. The dimensionless effective flange width coefficient was used to assess the degree of shear lag effect on the effective flange width and was obtained by the theoretical formula derived from the principle of minimum potential energy.

3. The FE models were validated by comparison with the experiment results, which can be used to simulate the normal stress distribution of the section with good accuracy. The parametric study conducted by the FE models demonstrates that the axial load ratio and height-width ratio of flange are the main determinants of the effective flange width coefficient.

4. Based on the finite element results, a simplified formula of the effective flange width coefficient in the elastic stage was obtained by the nonlinear fitting of the function model, which was proposed by the parametric study. The comparison between the

\section{References}

[1] Song, Q. G., Scordelis, A. C. "Shear-Lag Analysis of T-, I-, and Box Beams", Journal of Structural Engineering, 116(5), pp. 12901305, 1990.

https://doi.org/10.1061/(ASCE)0733-9445(1990)116:5(1290)

[2] Chiewanichakorn, M., Aref, A. J., Chen, S. S., Ahn, I. S. "Effective Flange Width Definition for Steel-Concrete Composite Bridge Girder", Journal of Structural Engineering, 130(12), pp. 20162031, 2004.

https://doi.org/10.1061/(ASCE)0733-9445(2004)130:12(2016)

[3] Lin, Z. B., Zhao, J. "Modeling inelastic shear lag in steel box beams", Engineering Structures, 41, pp. 90-97, 2012. https://doi.org/10.1016/j.engstruct.2012.03.018

[4] Taleb, R., Watanabe, H., Kono, S. "Numerical Study on the Ultimate Deformation of RC Structural Walls with Confined Boundary Regions", Periodica Polytechnica Civil Engineering, 62(1), pp. 191-199, 2018.

https://doi.org/10.3311/PPci.10554 predictions of the formula and the theoretical solutions shows that the simplified formula can perfectly predict the results. Then, the simplified formulas of the effective flange width coefficient at the yield and limit states were fitted by the same method. However, the axial load ratio determines the compression zone depth in the limit state, which forms a power formula instead of the linear relationship between the axial load ratio and the effective flange width coefficient. It was shown that these simplified formulas are both in a good agreement with the FE results, thus they are capable of predicting the effective flange width of T-shaped shear walls.

\section{Acknowledgement}

The work presented in this paper was financially supported by the National Natural Science Foundation of China (Grant No. 51778143) and the Priority Academic Program Development of Jiangsu Higher Education Institutions (No. CE02-1-51).

[5] Wang, B., Shi, Q. X., He, W. F. “带翼缘剪力墙有效翼缘宽度的解 析解与简化公式” (Analytical solution and simplified formulas for effective flange width of flanged shear walls), Journal of Harbin Engineering University, 38(3), pp. 404-411, 2017. (in Chinese) https://doi.org/10.11990/jheu.201510039

[6] Kwan, A. K. H. "Shear Lag in Shear/Core Walls", Journal of Structural Engineering, 122(9), pp. 1097-1104, 1996. https://doi.org/10.1061/(ASCE)0733-9445(1996)122:9(1097)

[7] Luo, S. L., Li, Q. N. "短肢剪力墙的剪滞效应及其影响分析" (Shear lag in short leg walls and its effects), Journal of Xi'an University of Architecture and Technology, 35(4), pp. 329-333, 2003. (in Chinese)

http://doi.org/10.3969/j.issn.1006-7930.2003.04.006

[8] Li, Q. N., Zhang, P. L., Li, X. L. "短肢剪力墙剪滞效应分析" (Shear lag effect analysis of short pier shear wall), Industrial Construction, 41(9), pp. 59-62, 2011. (in Chinese) http://doi.org/10.13204/j.gyjz2011.09.029 
[9] Chaouch, A. A., Boutemeur, R., Bechtoula, H., Bali, A. "Numerical Study on Shear Stress Variation of RC Wall with L-Shaped Section", Periodica Polytechnica Civil Engineering, 59(1), pp. $15-25,2015$.

https://doi.org/10.3311/PPci.7575

[10] Hassan, M., El-Tawil, S. "Tension Flange Effective Width in Reinforced Concrete Shear Walls", Structural Journal, 100(3), pp. 349-356, 2003. https://doi.org/10.14359/12610

[11] Zhang, Z. W., Li, B. "Shear lag effect in tension flange of RC walls with flanged sections", Engineering Structures, 143, pp. 64-76, 2017. https://doi.org/10.1016/j.engstruct.2017.04.017

[12] Li, Q. N., Zhang, J. M., Luo, S. L., Lu, H. Y. "短肢剪力墙剪滞效 应的变分解法" (Variational solution of shear-lag effect of shortleg shear wall), Journal of Xi'an University of Architecture and Technology, 36(1), pp. 32-34, 2004. (in Chinese) https://doi.org/10.15986/j.1006-7930.2004.01.007

[13] Zhang, S. J., Li, Q. N., Guo, Z., Zhang, J. "形截面短肢剪力墙剪 滞效应及其影响" (Shear lag and its effects of t-shaped short-leg shear wall), Industrial Construction, 37(10), pp. 38-41, 2007. (in Chinese) https://doi.org/10.13204/j.gyjz2007.10.011

[14] Ni, X. Y., Cao, S. Y. "Shear lag analysis of I-shaped structural members", The Structural Design of Tall and Special Buildings, 27(10), Article number: e1471, 2018. https://oi.org/10.1002/tal.1471

[15] Reissner, E. "Analysis of shear lag in box beams by the principle of minimum potential energy", Quarterly of Applied Mathematics, 4, pp. 268-278, 1946. https://doi.org/10.1090/qam/17176

[16] Liu, C. Q., Wei, X., Wu, H., Li, Q., Ni, X. Y. "Research on Shear Lag Effect of T-shaped Short-leg Shear Wall", Periodica Polytechnica Civil Engineering, 61(3), pp. 602-610, 2017. https://doi.org/10.3311/PPci.9491

[17] Ni, X. Y., Cao, S. Y., Liu, C. Q. "Shear lag and effective flange width of T-shaped short-leg shear walls", Journal of Engineering Research, 6(1), pp. 31-52, 2018.

[18] Zhang, Y. L., Li, Y. S., Fan, J. S., Ji, W. Y. "钢-混凝土组合梁负弯 矩区有效翼缘宽度的研究" (Study of the shear lag effect and the effective flange width at negative moment zone of steel-concrete composite beams), Engineering Mechanics, 27(2), pp. 178-185, 2010. (in Chinese)
[19] Shi, Q. X., Wang, B., Zheng, X. L., Tian, J. B. "T形截面带翼缘剪 力墙剪滞效应分析及有效翼缘宽度讨论" (Shear lag effect analysis and effective flange width study of the T-shaped shear wall with flange), Building Structure, 44(22), pp. 67-71, 2014. (in Chinese) https://doi.org/10.19701/j.jzjg.2014.22.015

[20] Shi, Q. X., Wang, B. "Simplified calculation of effective flange width for shear walls with flange", The Structural Design of Tall and Special Buildings, 25(12), pp. 558-577, 2016. https://doi.org/10.1002/tal.1272

[21] Zhang, Y. H., Lin, L. X. "Shear lag analysis of thin-walled box girders based on a new generalized displacement", Engineering Structures, 61, pp. 73-83, 2014. https://doi.org/10.1016/j.engstruct.2013.12.03

[22] Zhang, Y. H., Bai, X., Lin, L. X. "箱形梁剪力滞效应的改进分析 方法研究" (Improved approach for analyzing shear lag effect of box girders), China Civil Engineering Journal, 45(11), pp. 153-158, 2012. (in Chinese) https://doi.org/10.15951/j.tmgexb.2012.11.005

[23] ANSYS Inc. "ANSYS, (14.0)", [computer program] Available at: http://www.ddooo.com/softdown/75064.htm [Accessed:06 December 2019]

[24] Wang, X. M. "ANSYS工程结构数值分析" (ANSYS Engineering Structure Numerical Analysis), China Communications Press, Beijing, China, 2007. (in Chinese)

[25] Ministry of Housing and Urban-Rural Development of the People's Republic of China "GB50010-2010 混凝土结构设计规 范" (GB 50010-2010. Code for Design of Concrete Structures), Construction industry press, Beijing, China, 2010. (in Chinese)

[26] Li， X. L. "高层建筑短肢剪力墙结构的力学模型与试验研究" (Mechanical model and test study of High-rise building on short-leg shear wall structure), PhD Thesis, Xi'an University of Architecture and Technology, 2011. (in Chinese)

[27] 7D-Soft High Technology Inc. "1Stopt, (V1.5)", [computer program], Available at: http://www.ddooo.com/softdown/149193.htm [Accessed: 06 December 2019]

[28] Ministry of Housing and Urban-Rural Development of the People's Republic of China "JGJ 3-2010 高层建筑混凝土结构技术规程" (JGJ 3-2010 Technical Specification for Concrete Structure of Tall Buildings), Construction industry press, Beijing, China, 2010. (in Chinese) 